\title{
A Position Sensor with Novel Configuration of Linear Variable Differential Transformer
}

\author{
Mehran Mirzaei, Member, IEEE, Pavel Ripka, Member, IEEE, and Vaclav Grim, Student Member, IEEE
}

\begin{abstract}
This paper presents a position sensor based on a novel configuration of linear variable differential transform er. Design and optimization of the position sensor are presented using finite element method. The sensor has short air core coils and long magnetic armatures. The arrangement direction of the rectangular excitation coil and two antiserially connected rectangular pick up coils is perpendicular to the motion direction of the position sensor. The coils are located be tween two parallel silicon steel laminations as the armatures. The position sensor is optimized with compromise between minimization of nonlinearity error and maximum se nsitivi ty. The main advantage of the proposed position sensor is the small ratio of coils dimensions to the working range. The position sensor is operated for the measurements and calculations at excit ation freque ncies, $500 \mathrm{~Hz}$ and $1000 \mathrm{~Hz}$ and $2000 \mathrm{~Hz}$. The maximum nonlinearity error is less than $1.5 \%$ for theoretical analysis and it is less than $2 \%$ for the measurement results in $\pm 90 \mathrm{~mm}$ position range.
\end{abstract}

Index Terms - Position sensor, linear variable differential transformer, design and optimization, finite element meth od

\section{INTRODUCTION}

$\mathrm{T}$ HE position sensing and position sensors have a key role in various industrial applications and machineries with translational and rotational moving components [1]-[8]. The types of conventional position sensors are potentiometric, linear variable differential transformer (LVDT), optical, magnetostrictive, and magnetometer based, for example, magnetic Hall sensor.

Potentiometric position sensors have high accuracy, economical and simple signal processing [9]-[10]. However, they are sensitive to the wear, dust, and temperature. LVDT position sensors have high accuracy with lower sensitivity to the working environment [1] and [11]-[15]. They could be quite expensive and bulky because of the coils. Optical positions sensors are inflexible, sensitive to the dust and temperature despite their high accuracy and excellent resolution. Magnetometer based position sensors are sensitive to the magnetic objects and electrical noises, which affect their accuracy in position sensing [2] and [7]. Magnetostrictive position sensors [16] with high accuracy for long distance are sensitive to environment temperature, not costeffective and with less accuracy for short distance operation.

Thiswork was supported in part by the Czech Technical Universi ty in Prague under Grant SGS18/187/OHK3/3T/1

M. Mirzaei is with Faculty of Electrical Engineering, Czech Technical University, Prague 16627, Czech Republic (e-mail: mirzameh@fel.cvut.cz).

P. Ripka is with Faculty of Electrical Engineering, Czech Tech nical University, Prague 16627, Czech Republic (e-mail: ripka@fel.cvut.cz).

V. Grimi is with Faculty of Electrical Engineering, Czech Technical University, Prague 16627, Czech Republic (e-mail: vaclav.grim@fel.cvut.cz).
Position sensor based on variable inductance or impedance were presented in [17]-[19], which has bulky winding and heavy weight for long length measurements. Position sensors us ing magnetically coupled coils and short-circuited moving coil and air coil structure were designed and meas ured in [20][21]. However, these sensors suffer from low s en s or ou tput sensitivity and low immunity to the external adjacent magnetic objects. A variable reluctance differential solen oid transdu cer for position sensing was validated for high precision in [22], which is only shown for short lengths and it could be very bulky and heavy for large distance measuring. A perman ent magnet linear resolver was us ed for position sensing for long distance in [23]. However, it needs salient secondary magnetic part with high precision punched or machine tooled and $\mathrm{NdFeB}$ permanent magnets with less appropriateness for harsh environments. Authors developed and presented long length position sensor for $500 \mathrm{~mm}$ working for pneumatic and hydraulic cylinders applications with small size coils and a conical solid iron rod [24].

A novel configuration of LVDT is utilized for position sensing in this paper with short coils and long armatures for long distanceposition measurements. The sensor can detect positive and negative movements as conventional LVDTs. The goal is to design a position sensor with highest simplicity for its structure and performance and to be cost effective. Armatures are only two silicon steel laminations with $0.5 \mathrm{~mm}$ thickness, which have been angularly shifted to the coils plane. Unlike the conventional LVDT sensor, the sizes of excitation and pick up coils are unchanged in th is s ensor to measure longer distance positions. 2D and 3D finite element method (FEM) is used for the performance analysis and design. The position sensor is designed and optimized to have high output sensitivity and low non linearity error. 


\section{BASIC STUDY AND STRUCTURE}

Fig. 1 shows schematic 2D model of the position sensor, which consists of two armatures, one excitation coil and two antis erially connected pick up coils. The two armatures are in parallel and they are angularly shifted with angle, $\beta$ relative to the coils in the horizontal plane (Fig. 1). Fig. 2 depicts schematic magnetic flux distributions at different relative positions of the coils and the armatures.

Equation (1) presents relationship between differential voltage, $U_{\mathrm{d}}$ and each pick up voltage, $U_{1}$ and $U_{2}$.

$$
\begin{aligned}
& U_{1}=-j \omega \cdot \Psi_{1} \\
& U_{2}=-j \omega \cdot \Psi_{2} \\
& \omega=2 \pi \cdot f \\
& U_{d}=U_{2}-U_{1}=-j \omega \cdot \Psi_{\mathrm{d}}, \Psi_{\mathrm{d}}=\Psi_{2}-\Psi_{1}
\end{aligned}
$$

Where, the differential flux linkage, $\Psi_{\mathrm{d}}$ is $\Psi_{2}-\Psi_{1}$, which $\Psi_{2}$ and $\Psi_{1}$ are flux linkage of pick up coils. $f$ is the excitation frequency.

The upper and lower pick up coils have same flux linkage $\left(\Psi_{2}=\Psi_{1}\right)$ when they are located in the center position of armatures and their differential voltage is zero. However, the differential voltage value becomes negative or positive when the relative positions of the coils to the armatures are moved to the left or right directions. Because the flux linkages in pick up coil are different $\left(\Psi_{2} \neq \Psi_{1}\right)$ as dis tance between them and armatures are not the same as shown in Fig. 2.

3D model and dimensions of the position sensor are shown in Fig. 3. The number of turns in all coils is 500. The longitudinal length of armatures is $300 \mathrm{~mm}$. The mean wid th, $w_{\mathrm{m}}$ and height, $h$ of each coil are $11.6 \mathrm{~mm}$ and $5 \mathrm{~mm}$ as shown in Fig. 3. The position sensor performance is studied and measured at excitation frequencies, $500 \mathrm{~Hz}, 1000 \mathrm{~Hz}$ and 2000 $\mathrm{Hz}$ with corres ponding measured current amplitudes, $I_{\mathrm{m}}, 84.7$ $\mathrm{mA}, 83.0 \mathrm{~mA}$ and $79.4 \mathrm{~mA}$, res pectively.

\section{FEM STUDY}

2D and 3D time harmonic FEM [25] are used for the steady state performance analysis of the position sensor. The magnetic flux density is very low in the steel lamination of armatures as shown Fig. 4. Therefore, linear magnetic simulations are performed. And initial relative magnetic permeability, $\mu_{\mathrm{r}}=1000$ for the steel lamination is estimated and considered for the FEM analysis [13] and [26]. The conductivity of steel lamination was measured, which is $\sigma=$ $3.14 \mathrm{MS} / \mathrm{m}$. The induced eddy current in the steel lamination s is considered (Fig. 5) in the FEM analys is .

The following differential equations extracted from Maxwell equations are used in time harmonic magnetic field analys is:

$$
\begin{aligned}
& \nabla \times H=J \\
& \nabla \bullet B=0 \rightarrow B=\nabla \times A \\
& \nabla \times J=-j \omega \sigma \cdot B
\end{aligned}
$$

where, $H, J, B$, and $A$ are magnetic field strength, current density, magnetic flux density, and magnetic vector potential, respectively. Magnetic vector potential has only one unknown component, $A_{\mathrm{z}}$ in 2D analys is. But it has three unknowns, $A_{\mathrm{x}}$, $A_{\mathrm{y}}$ and $A_{\mathrm{z}}$. Therefore, 3D analysis is more time consuming and it needs more memory.

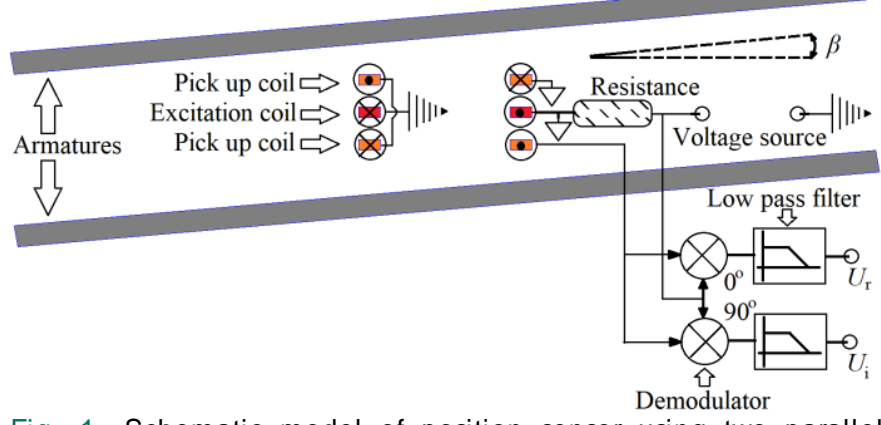

Fig. 1. Schematic model of position sensor using two parallel armatures with LVDT configuration and sensor measurement syste $\mathrm{m}$ using a lock in amplifier

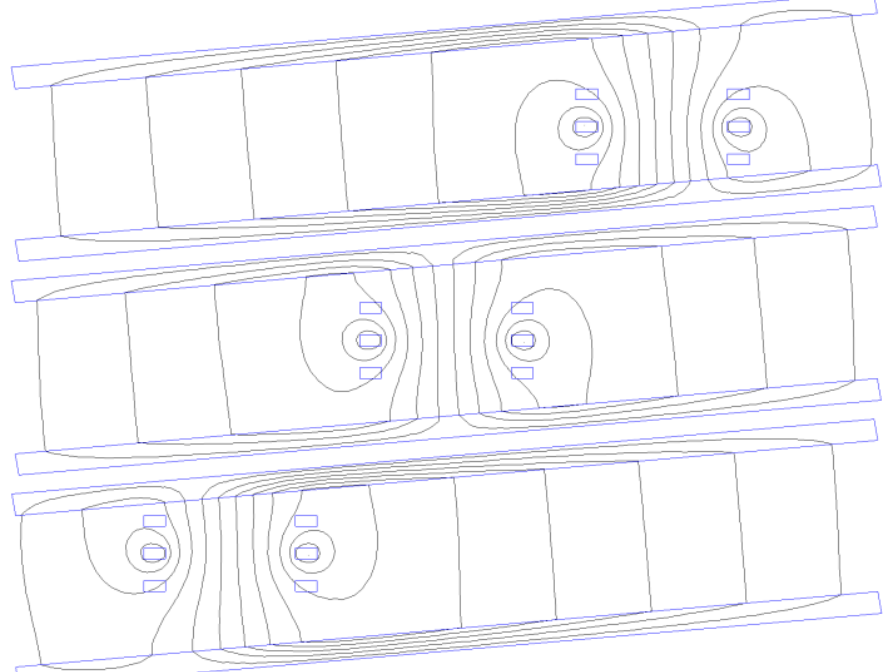

Fig. 2. Schematic magnetic flux distribution in the sensor at different relative positions of the coils relative to the armatures

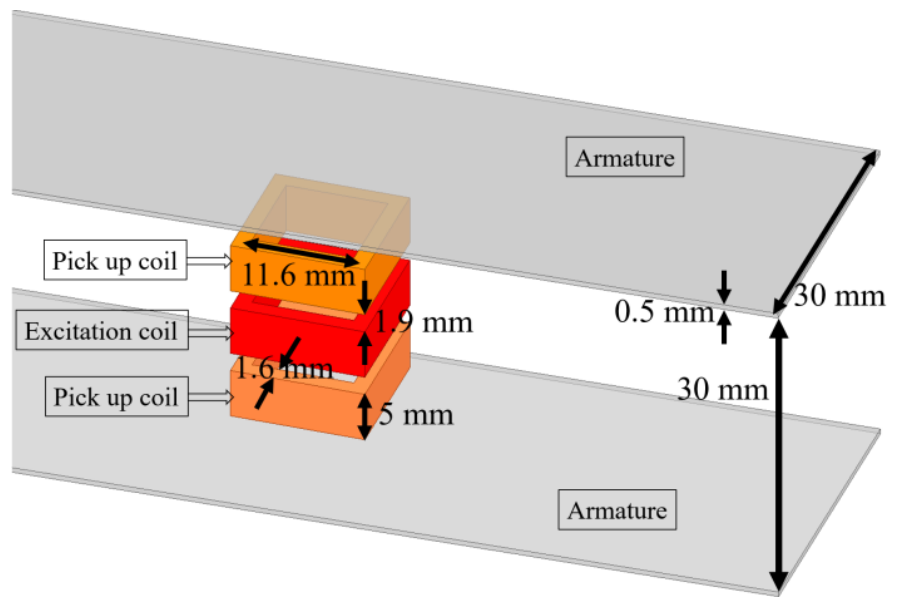

Fig. 3. 3D model of the position sensor and itsdimensions 


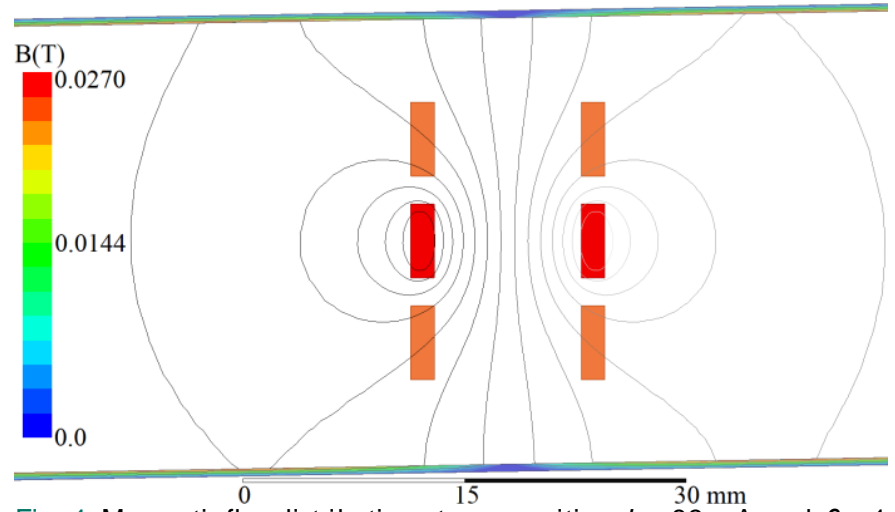

Fig. 4. Magnetic flux distribution at zero position, $I_{m}=83 \mathrm{~mA}$ and $\beta=1$ deg., and $d=0 \mathrm{~mm}-2 \mathrm{D} \mathrm{FEM}$

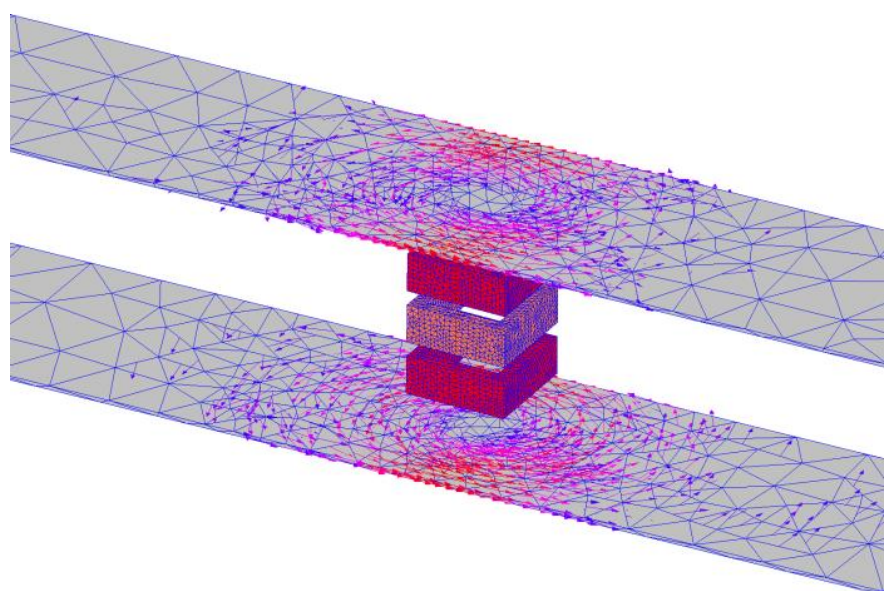

Fig. 5. 3D FEM meshed model of position sensor and induced eddy current in conductive silicon steel lamination with $0.5 \mathrm{~mm}$ thickness
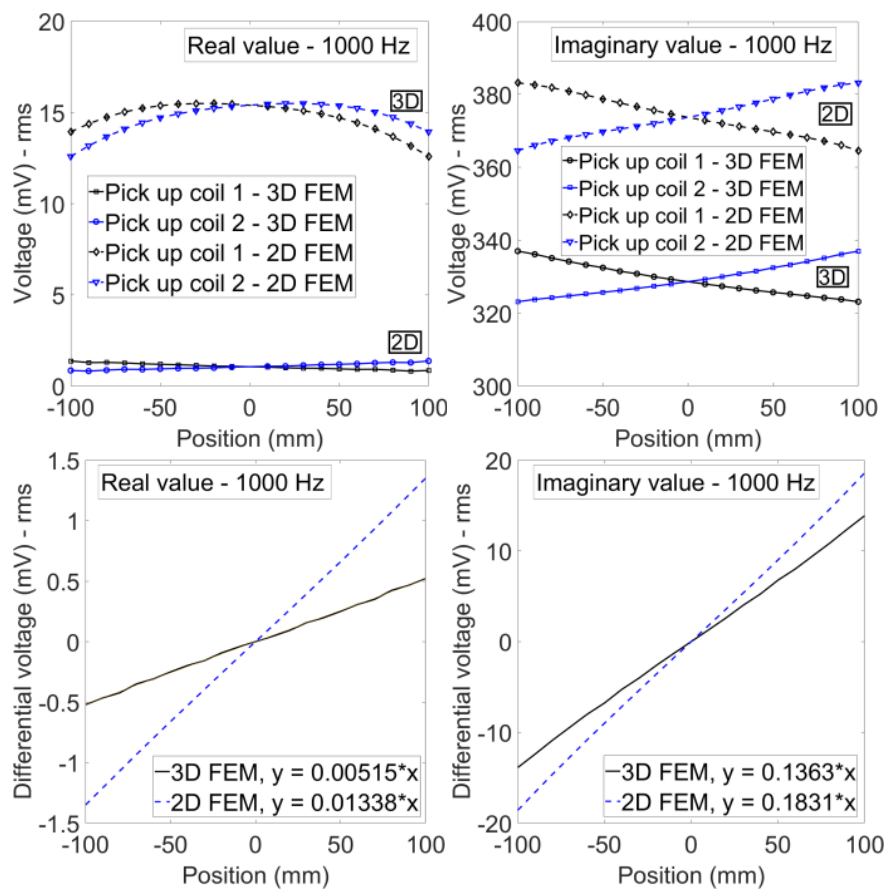

Fig. 6. The voltages of each pick up coils $\left(U_{1}\right.$ and $\left.U_{2}\right)$ and their differential voltage $\left(U_{2}-U_{1}\right)$ at $1000 \mathrm{~Hz}, l_{\mathrm{m}}=83 \mathrm{~mA}$ and $\beta=1.0 \mathrm{deg}$. 2D FEM vs 3D FEM
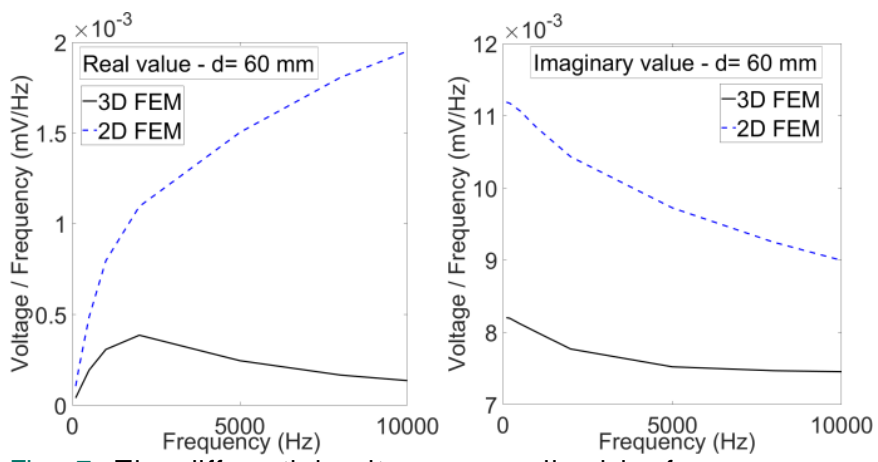

Fig. 7. The differential voltages normalized by frequency versus frequency, $I_{m}=83 \mathrm{~mA}, \beta=1$ deg., and $d=60 \mathrm{~mm}-2 \mathrm{D} \mathrm{FEM} \mathrm{vs} \mathrm{3D}$ FEM

The FEM analys es of the position sensor are performed in $\pm 100 \mathrm{~mm}$ range. Fig. 6 shows the voltages of each pick up coil and their differential voltage versus position with $\beta=1 \mathrm{deg}$. Real and imaginary components of voltages are calculated relative to the current of the excitation coil as a reference signal. Real component of voltage is caused by induced eddy currents in the conductive steel lamination of armatu res. 3D FEM results shows less value in comparison with 2D FEM because of $3^{\text {rd }}$ dimension effects (transverse effects), which is not considered in the 2DFEM. The model depth in transverse direction is considered $11.6 \mathrm{~mm}$ in 2D FEM, which is equal to the mean width of coil, $w_{\mathrm{c}}$ in Fig. 3. The differential voltag es show linear curve versus positions in Fig. 6, which could be utilized as a position indicator.

The differential voltage to frequency ratio is depicted in Fig. 7 up to $10 \mathrm{kHz}$ with $\beta=1 \mathrm{deg}$., which is equivalent to differential flux linkage, $\Psi_{2}-\Psi_{1}$ in (1). It shows that the imaginary component of voltage is considerable higher than real component of voltage similar to the results in Fig. 6. The voltage to frequency ratio is decreasing with increasing frequency because of skin effects in the conductive steel laminations. Using nonconductive ferromagnetic armatures, for example, Ferrite will cancel frequency dependency of voltage to frequency ratio and diminish real component of voltage.

Absolute value of voltage, $U_{\mathrm{A}}$ can be also utilized for position sensing as both real, $U_{\mathrm{R}}$ and imaginary, $U_{\mathrm{I}}$ components are linear curveversus position.

$U_{\mathrm{A}}=\sqrt{U_{\mathrm{R}}^{2}+U_{\mathrm{I}}^{2}}$

Absolute value of voltage is almost as imaginary component of voltage as real component voltage is much smaller especially at operating frequency, $1000 \mathrm{~Hz}$.

The differential voltages and nonlinearity full scale errors for different armatures shifting angles, $\beta$ are presented in Fig. 8 . The differential voltage is higher for bigger shifting angles, $\beta$. However, maximum nonlinearity full scale error is also increasing with bigger $\beta$. The calculated imaginary component of differential voltage has lower nonlinearity error, which makes it more suitable for position indicating at $\beta=0.5 \mathrm{deg}$. and $1.0 \mathrm{deg}$. 

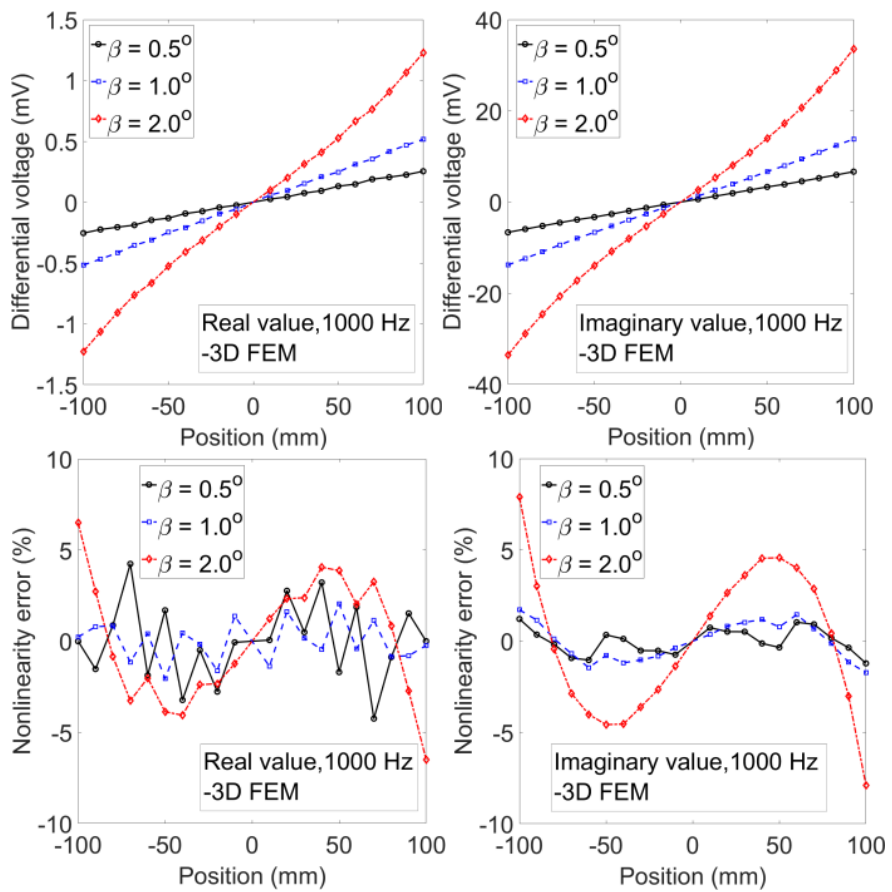

Fig. 8. The differential voltage and nonlinearity error at $1000 \mathrm{~Hz}$, and $I_{m}$ $=83 \mathrm{~mA}$ versus armaturesangles, $\beta$
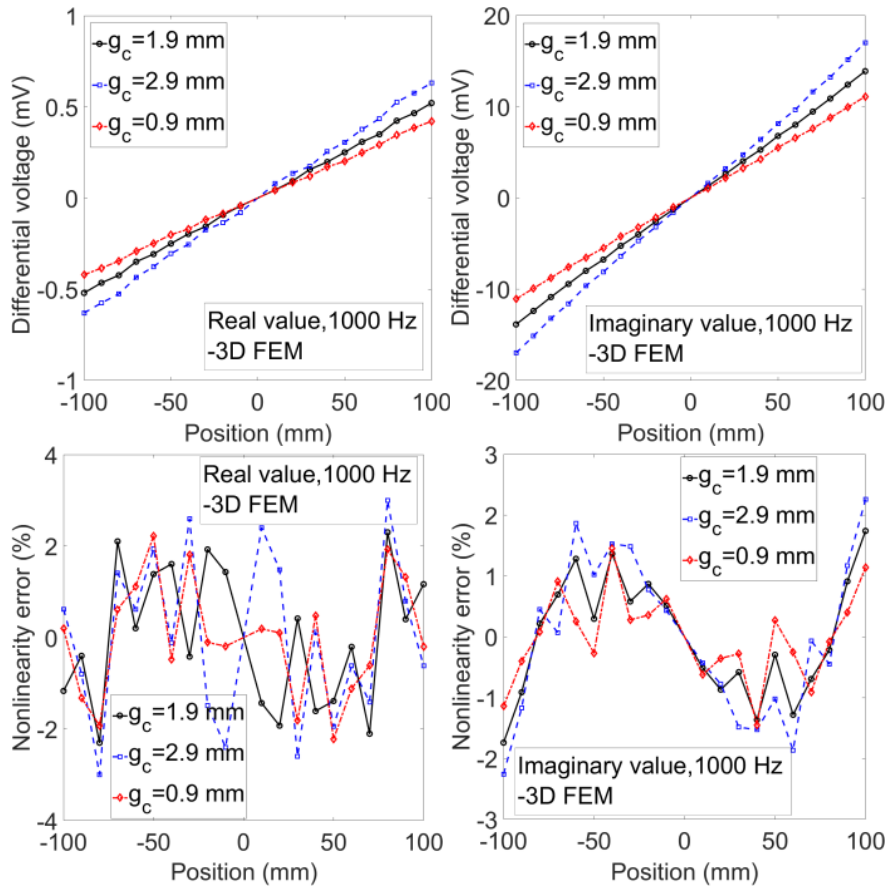

Fig. 9. The differential voltage and nonlinearity error at $\beta=1.0 \mathrm{deg}$., and $l_{m}=83 \mathrm{~mA}$ versus gap between excitation coil and pickup coils, $g_{c}$

Increasing gap dis tance between excitation coil and pick up coils, $g_{c}$ increasing differential voltage with expense of increasing maximum nonlinearity full scale error as shown in Fig. 9. Selecting gap distance, $g_{\mathrm{c}}=1.9 \mathrm{~mm}$ and armatures shifting angles, $\beta=1.0 \mathrm{deg}$. is compromise between maximu $\mathrm{m}$ differential voltage and minimizing of maximum nonlinearity full scale error.

Table I shows sensitivity coefficients, $K_{\mathrm{R}}$ and $K_{\mathrm{I}}$ of real and imaginary components of the differential voltage for different relative magnetic permeability, $\mu_{\mathrm{r}}$ of silicon steel lamination of armatures. They are calculated based on linear curve fitting:

$U_{\mathrm{R}}=K_{\mathrm{R}} \cdot X$

$U_{\mathrm{I}}=K_{\mathrm{I}} \cdot X$

where, $X$ is relative position of the coils and the armatures. Increasing or decreasing relative magnetic permeability, $\mu_{\mathrm{r}}$ about $25 \%$ causes about $10 \%$ change in real component sensitivity, $K_{\mathrm{R}}$ and only $0.6 \%$ to $0.7 \%$ in imaginary component sensitivity, $K_{\mathrm{I}}$.

TABLE I

SENSITIVITY FACtORS FOR DifFERENT PERMEABILITY - 3D FEM

\begin{tabular}{ccc}
\hline \hline$\mu_{\mathrm{r}}$ & $K_{\mathrm{R}}(\mathrm{mV} / \mathrm{mm})$ & $K_{\mathrm{I}}(\mathrm{mV} / \mathrm{mm})$ \\
\hline 750 & $0.005654(109.7 \%)$ & $0.1348(99.3 \%)$ \\
1000 & $0.005154(100.0 \%)$ & $0.1358(100.0 \%)$ \\
1250 & $0.004623(89.7 \%)$ & $0.1366(100.6)$ \\
\hline \hline
\end{tabular}

\section{EXPERIMENTAL RESULTS}

The position sensors and experimental elements are s ho wn in Fig. 10 and Fig. 11. Lock in amplifier is used for the voltage measurements of antiserially pick up coils. A signal generator with internal res is tance $50 \Omega$ is connected in s eries with excitation coil as source voltage. Also, an external $5.85 \Omega$ resistance is connected in series with excitation coil and signal generator. It is utilized to measure the current of the excitation coil as a reference signal for the lock in amplifier, which real and imaginary components of pick coil voltage are finally measured relative to the reference signal. The schematic model of voltage measurement using lock in amplifier is als o illus trated in Fig. 1. The reference position sensor in Fig. 11 is a potentiometertype.

Firstly, measured inductances of excitation coil and antiserially connected pick up coils and 3D time harmonic FEM calculations were evaluated with and without silicon steel laminations of armatures for the initial assessment of modeling. The results are presented in Table II and Table III at $500 \mathrm{~Hz}, 1000 \mathrm{~Hz}$ and $2000 \mathrm{~Hz}$. The 3D FEM results match better with measurements for pick up coils inductances, $L_{\mathrm{PK}}$, however, they are also in adequate range for excitation coil inductances, $L_{\mathrm{EC}}$. The pick up coils inductances are more sensitive to armature position, $d$ than excitation coil inductances.

TABLE II

COMPARISON BETWEEN EXPERIMENTAL AND 3D FEM - INDUCTANCES WITHOUT ARMATURES

\begin{tabular}{ccc}
\hline \hline & $L_{\mathrm{EC}}(\mathrm{mH})$ & $L_{\mathrm{PK}}(\mathrm{mH})$ \\
\hline Exp. & 3.470 & 6.2285 \\
3D FEM & 3.3279 & 6.2220 \\
\hline \hline
\end{tabular}

TABLE III

COMPARISON BETWEEN EXPERIMENTAL AND 3D FEM - INDUCTANCES WITH ARMATURES

\begin{tabular}{ccccc}
\hline \hline & $d=0 \mathrm{~mm}$ & $d=0 \mathrm{~mm}$ & $d= \pm 100 \mathrm{~mm}$ & $d= \pm 100 \mathrm{~mm}$ \\
& $L_{\mathrm{EC}}(\mathrm{mH})$ & $L_{\mathrm{PK}}(\mathrm{mH})$ & $L_{\mathrm{EC}}(\mathrm{mH})$ & $L_{\mathrm{PK}}(\mathrm{mH})$ \\
$f(\mathrm{~Hz})$ & Exp./ & Exp./ & Exp./ & Exp./ \\
& 3D FEM & 3D FEM & 3D FEM & 3D FEM \\
500 & $3.5190 /$ & $6.3910 /$ & $3.5195 /$ & $6.4170 /$ \\
& 3.3806 & 6.3955 & 3.3811 & 6.4408 \\
1000 & $3.5187 /$ & $6.390 /$ & $3.5187 /$ & $6.4158 /$
\end{tabular}




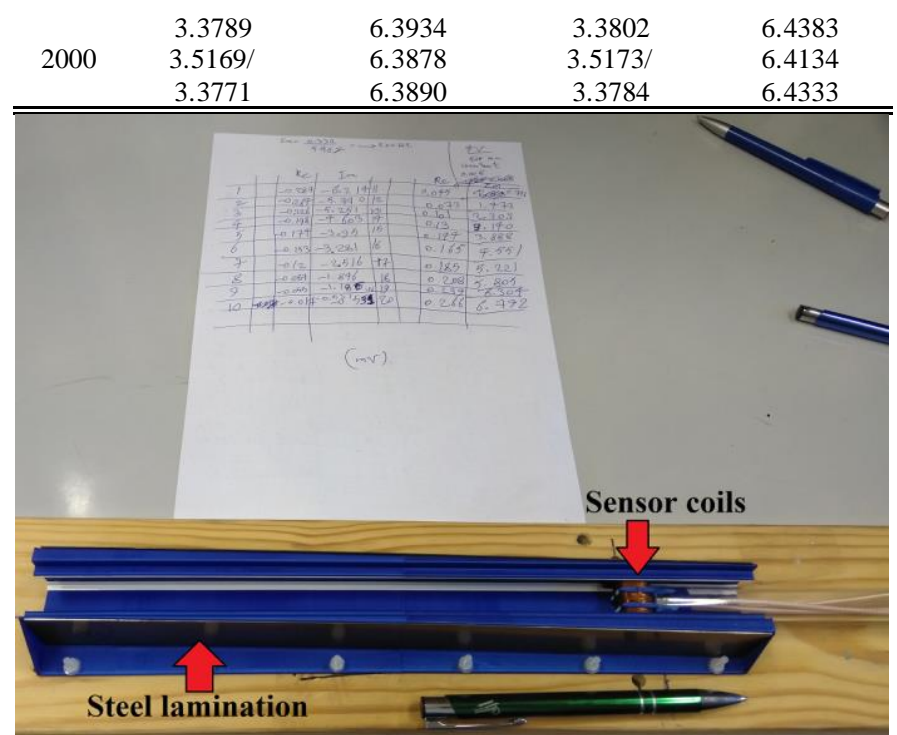

Fig. 10. The position sensor - Excitation coil, pickup coils and steel laminations

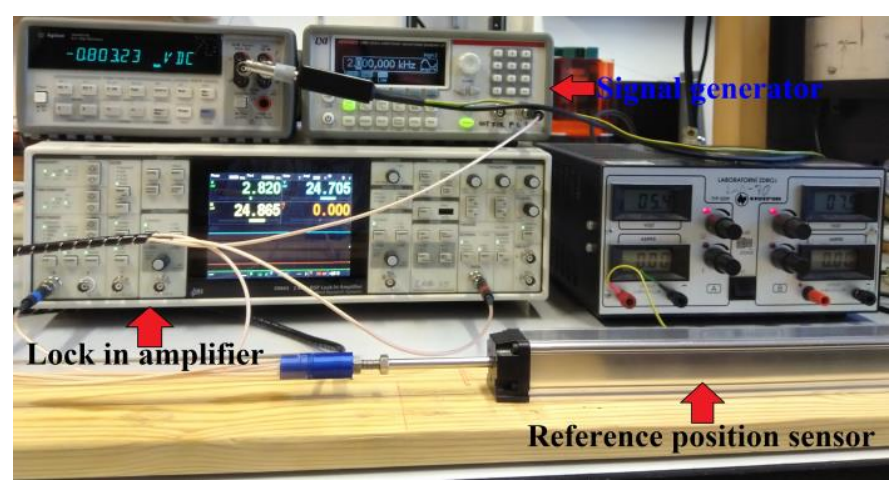

Fig. 11. Experimental elements-lockin amplifier, signal ge nerator, and reference position sensor

The measured real and imaginary components of differential voltage and their full scale nonlinearity errors versus position are presented in Fig. 12 at $500 \mathrm{~Hz}, 1000 \mathrm{~Hz}$ and $2000 \mathrm{~Hz}$. The measured real component of voltage curve is smaller and less linear in comparis on with imaginary component. The imaginary component sensitivity is about 8.6 times higher than real component sensitivity at $2000 \mathrm{~Hz}$ and it increases up to 14.0 and 23.7 at $1000 \mathrm{~Hz}$ and $500 \mathrm{~Hz}$, respectively.

The maximum nonlinearity error is close to the $5 \%$ for real component of voltage and it is less than $4 \%$ for imaginary component for $\pm 100 \mathrm{~mm}$ operating range. However, the maximum nonlinearity error is less than $2 \%$ for $\pm 90 \mathrm{~mm}$ operating range. The high nonlinearity error at $\pm 100 \mathrm{~mm}$ for armatures position is mainly caused by manufacturing tolerance. As this high nonlinearity error is absent in 3D FEM at $\pm 100 \mathrm{~mm}$ in Fig. 9. The full scale nonlinearity error is less than $1.5 \%$ for whole $\pm 100 \mathrm{~mm}$ working range in 3D FEM results.

High nonlinearity error of real component of differential voltage has not considerable effect on the absolute value of differential voltage as shown in Fig. 13. The sensitivity coefficient of absolute value of differential voltage, $K_{\mathrm{A}}$ increas es $0.7 \%$ in comparison with sensitivity coefficient of imaginary component at $2000 \mathrm{~Hz}$ and it increases $0.2 \%$ and $0.1 \%$ at $1000 \mathrm{~Hz}$ and $500 \mathrm{~Hz}$, respectively.
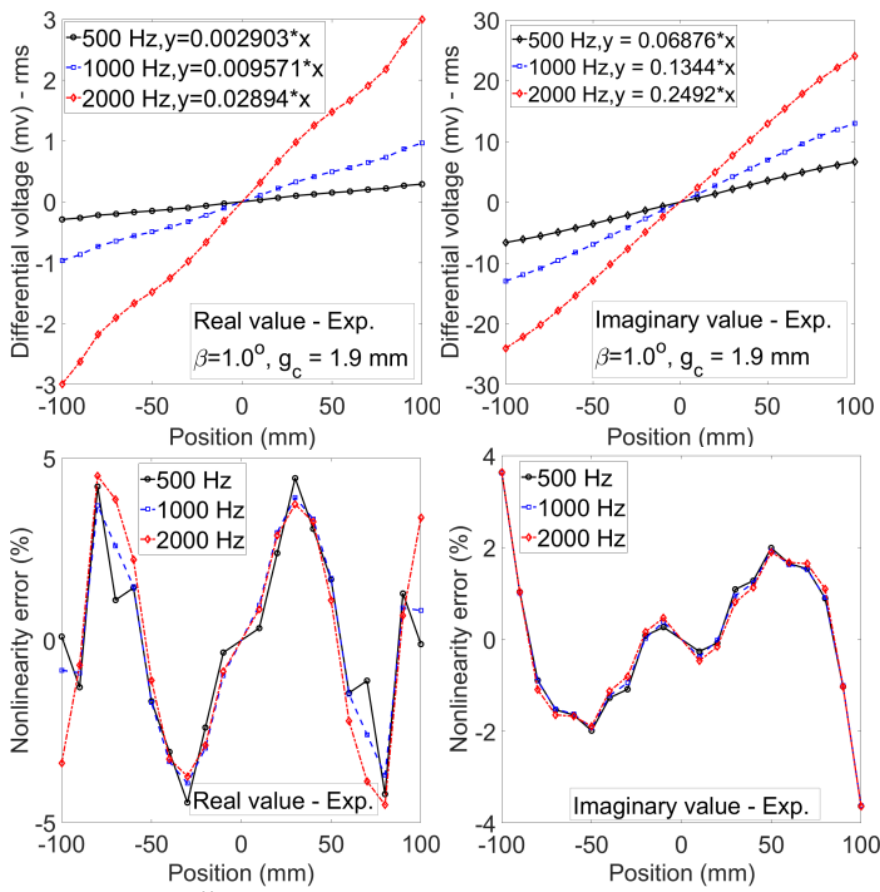

Fig. 12. The differential voltage and nonlinearity error - Experi me ntal results for real and imaginary components
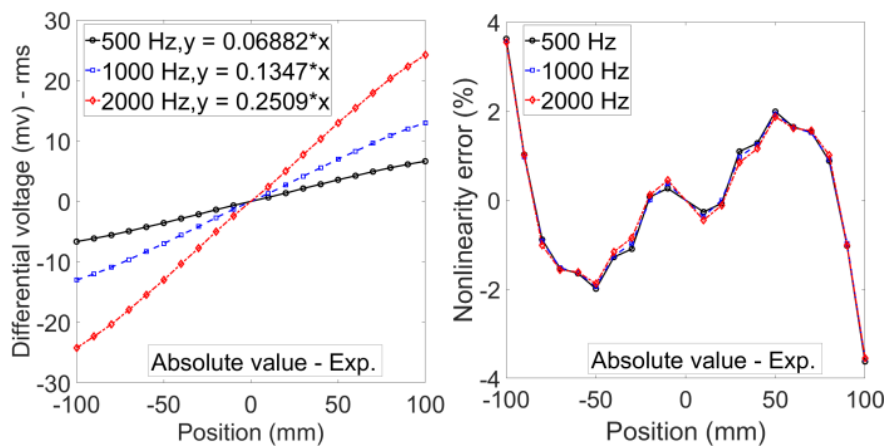

Fig. 13. The differential voltage and nonlinearity error - Experi mental results for absolute value

\section{DYNAMIC ANALYSIS}

The performance of the position sensors is important in dynamic conditions, especially, when the sensors have conductive components. The dynamic modeling using 2D time stepping FEM analysis of the position sensor at variable speeds are performed to evaluate motional induced eddy current effects on the sensor performance. The motional induced eddy current is generated when solid conducting armatures have relative speed to the excitation coil [27]-[29]. 2D time stepping FEM is used for the dynamic analysis despite its lower accuracy. Because it has less limitation in terms of number of meshes and memory, which is not straightforwardly conceivable in 3D time stepping FEM [30].

Two different speed profiles, 1 and 2 are selected for dynamic analysis for time range $100 \mathrm{~ms}$ as shown in Fig. 14. The positions of armatures, $d$ versus time change from $-60 \mathrm{~mm}$ 
to $+15 \mathrm{~mm}$ in both speed profiles, but they have different curves. The differential voltages versus armatures position are shown for speed profiles, 1 and 2 in Fig. 15 at $500 \mathrm{~Hz}$ and $1000 \mathrm{~Hz}$, which are the same for two speed profiles. It can be confidently mentioned that motionalcomponent of in duced eddy current in steel laminations has negligible effects on the performance of the position sensor.

\section{DISCUSSIONS}

Using ratiometric function $\left(\left(U_{2}-U_{1}\right) /\left(U_{2}+U_{1}\right)\right)$ reduces sensitivity of the position sensor to the armature material parameters, frequency and current of the excitation co il [11]. For example, Table IV shows sensitivity coefficients using ratiometric function $\left(K_{\mathrm{R}-\mathrm{r}}\right.$ and $\left.K_{\mathrm{I}-\mathrm{r}}\right)$ for relative magnetic permeability change, which shows maximum $3 \%$ change for real component sensitivity, $K_{\mathrm{R}-\mathrm{r}}$ and $0.4 \%$ to $0.6 \%$ in imaginary component sensitivity, $K_{\mathrm{I}-\mathrm{r}}$. It is les s sensitive to the relative magnetic permeability change in comparison with sensitivity coefficient in Table I. Therefore, ratiometric function could be also utilized to compensate material effects and temperature effects on the performance of the position sensor.
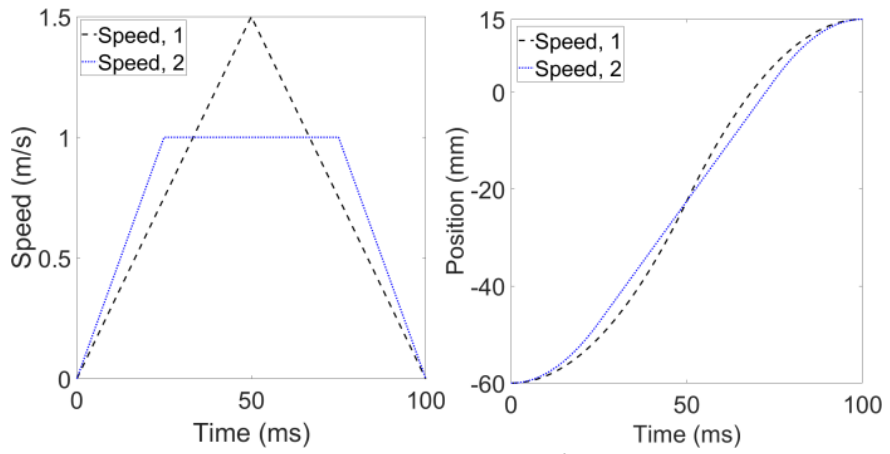

Fig. 14. Two applied time varying speed profiles
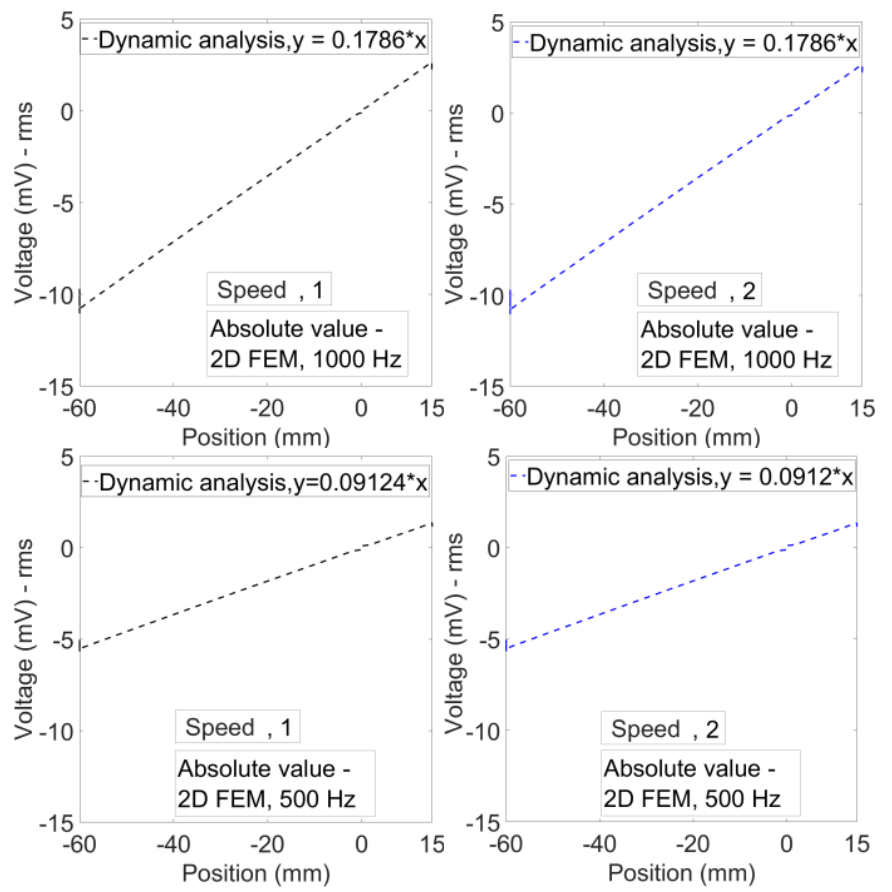

Fig. 15. The differential voltage versusposition in dynamic conditions2D FEM

TABLE IV

SENSITIVITY FACTORS OF RATIOMETRIC FUNCTION FOR DIFFERENT PERMEABILITY - 3D FEM

\begin{tabular}{ccl}
\hline \hline$\mu_{\mathrm{r}}$ & $K_{\mathrm{R}-\mathrm{r}}(1 / \mathrm{mm})$ & \multicolumn{1}{c}{$K_{\mathrm{I}-\mathrm{r}}(1 / \mathrm{mm})$} \\
\hline 750 & $0.002460(103.0 \%)$ & $0.0002048(99.4 \%)$ \\
1000 & $0.002388(100.0 \%)$ & $0.0002060(100.0 \%)$ \\
1250 & $0.002368(99.2 \%)$ & $0.0002069(100.4)$ \\
\hline \hline
\end{tabular}

Real and imaginary components of differential voltage versus frequency are measured and their ratio to frequency are shown in Fig. 16 at armature position, $d= \pm 60 \mathrm{~mm}$. The imaginary component is close to the $3 \mathrm{DFEM}$ simulations in Fig. 7, however, real component is closer to the 2D FEM.

Fig. 17 presents comparison between 3D FEM and experimental results for real and imaginary components of differential voltage versus position. The real co mp onent has higher discrepancy between measurements and 3D FEM, which is similar to the results comparison in Fig. 16. The highest discrepancy between experimental results and 3D FEM for imaginary component of differential voltage is occurred at $100 \mathrm{~mm}$ position of armature, which down bending of experimental curve causes high nonlinearity error as shown in Fig. 12 and Fig. 13.

Multi frequency electromagnetic method and compensation technique on phase signature could be also used to compensate the decentralization of coils and material effects in the position sensor [31]-[32] in addition to using ratiometric function [11]. Extension of linear range of the LVDT position sensors using techniques, for example, techniques based on the fractional order LVDT, LVDT inverse transfer characteristic and functional link artificial neural network allows sensor performance improvement for industrial applications [12], [14] and [33].
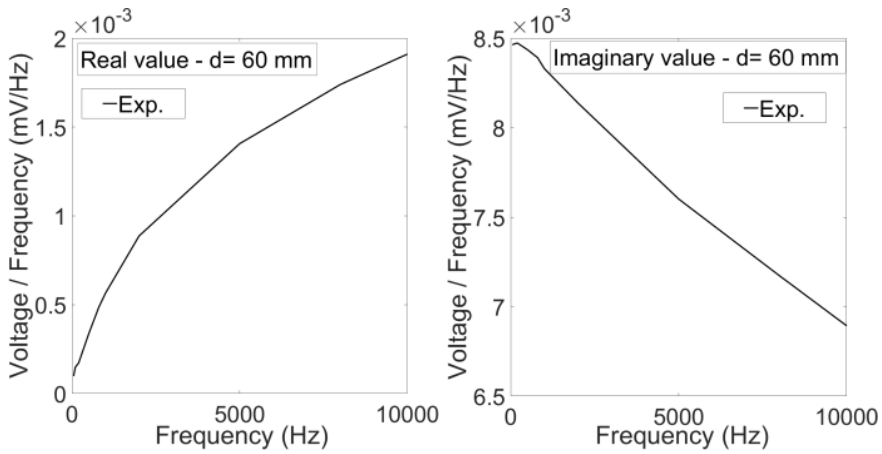

Fig. 16. The differential voltages normalized by frequency versus frequency, $I_{m}=83 \mathrm{~mA}, \beta=1$ deg., and $d=60 \mathrm{~mm}$ - Experimental 

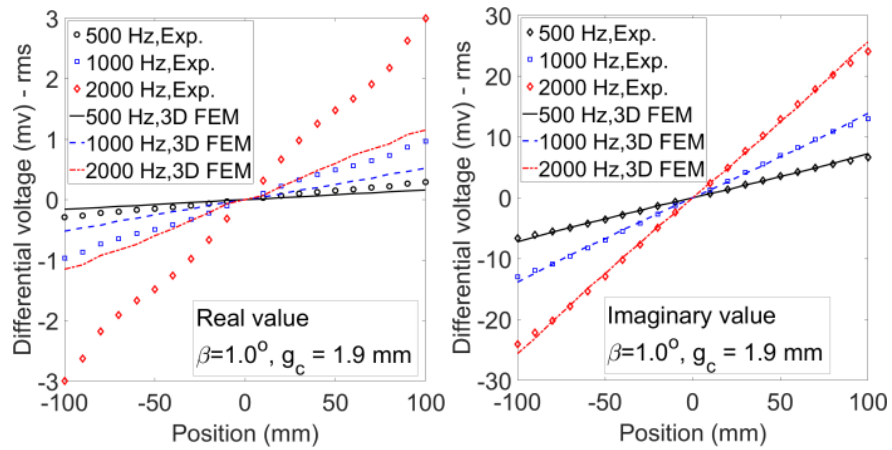

Fig. 17. The differential voltage-3D FEM vs Experimental results

\section{CONCLUSION}

The performance analysis and meas urements of the position sens or with novel structure were presented. The s ens or has simple configuration and it is cost effective, which makes it a suitable option for industrial applications and e cono mically mas s production. The small size of coils of the position sensor in comparison with armatures length and operating range makes it more fault tolerant in the harsh environment. And the position sensor is les s bulky in comparis on with its counterpart LVDT and potentiometer position sensors.

Conductive silicon laminations with $0.5 \mathrm{~mm}$ thicknes s were utilized for the armatures for easier manufacturing and lower material cost. However, it can be replaced with Ferrite, iron powder and soft magnetic composites rectang ular bars with much lower conductivity to suppress induced eddy currents and minimize real component of differential voltage.

The measured sensitivities of the position sensor are $0.251 \mathrm{mV} / \mathrm{mm}, 0.135 \mathrm{mV} / \mathrm{mm}$ and $0.069 \mathrm{mV} / \mathrm{mm}$ for absolute value of differential voltage at $2000 \mathrm{~Hz}, 1000 \mathrm{~Hz}$ and $500 \mathrm{~Hz}$, respectively. Maximum measured nonlinearity error is less than $2 \%$ in $\pm 90 \mathrm{~mm}$ working range.

Optimization of the position sensor in terms of increas ing sensitivity, reducing nonlinearity errors and extending linearity range is planned for the future works.

\section{REFERENCES}

[1] C. W. Clapp, "Use of saturable cores in linear differential transformers," IEEE Trans. Aerospace, vol. 2, no. 4, pp. 1134-1142, Oct. 1964

[2] S. Taghvaeeyan, R. Rajamani, and Z. Sun, "Non-intrusive piston position measurement system using magnetic field measurements," IEEE Sens. J., vol. 13, no. 8, pp. 3106-3114, Aug. 2013.

[3] M. Mirzaei, P. Ripka, A. Chirtsov, and V. Grim, "Temperature stability of the transformer position transducer for pneumatic cylinder," J. Mag. \& Mag. Mat., vol. 503, 166636, June 2020.

[4] P. Ripka, and A. Tipek, Modern Sensors Handbook. Chippenham, Wiltshire, UK: Wiley-ISTE, 2007, pp. 305-314

[5] X. Ge, Z. Q. Zhu, R. Ren, and J. T. Chen, "A novel variable reluctance resolver for HEV/EV applications," IEEE Trans. Ind. App., vol. 52, no. 4, pp. 2872-2880, Jul./Aug. 2016.

[6] A. S. A. Kumar, B. George, and S. C. Mukhopadhyay, "Technologies and applications of angle sensors: a review," IEEE Sens. J., vol. 21, no. 6, pp. 7195-7206, Mar. 2021.

[7] J. O. Manyala, T. Fritz, and M. Z. Atashbar, "Integration of triaxial HallEffect sensor technology for gear position sensing in commercial vehicle transmissions," IEEE Trans. Inst. \& Meas., vol. 61, no. 3, pp. 664-672 March 2012.

[8] J. Vcelak, Pavel Ripka, and Ales Zikmund, Long-range magnetic tracking system, IEEE Sens. J., vol. 15, no. 1, pp. 491-496, Jan. 2015.
[9] Y. Kim, H. Y. Choi, and Y. C. Lee, "Design and preliminary evaluation of high-temperature position sensors for aerospace applications," IEEE Sens. J., vol. 14, no. 11, pp. 4018-4025, Nov. 2014.

[10] Y. Kim, and H. Y. Choi, "A geometric design study of high-temperat ure position sensors," IEEE Sens. J., vol. 16, no. 19, pp. 7065-7072, Oct. 2016.

[11] S. C. Saxena, and S. B. Lal Seksena, "A self-compensated smart LVDT transducer," IEEE Trans. Ins. \& Meas., vol. 38, no. 7, pp. 748-753, June 1989.

[12] W. Petchmaneelumka, W. Koodtalang, and V. Riewruja, "Simple technique for linear-range extension of linear variable differential transformer," IEEE Sens. J., vol. 19, no. 13, pp. 5045-5051, Jul. 2019.

[13] M. Mirzaei, J. Machac, P. Ripka, A. Chirtsov, J. Vyhnanek, and V. Grim, "Design of a flat-type magnetic position sensor using a finitedifference method," IET Sc., Meas. \& Tech., vol. 14 no. 5, pp. 514-524, Jul. 2020.

[14] S. K. Mishra, G. Panda, and D. Prasad Das, "A novel method of extending the linearity range of linear variable differential transformer using artificial neural network," IEEE Trans. Ins. \& Meas., vol. 59, no. 4, pp. 947-953, April 2010

[15] G. Chen, B. Zhang, P. Liu, and H. Ding, "An adaptive analog circuit for LVDT's nanometer measurement without losing sensitivity and range," IEEE Sens. J., vol. 15, no. 4, pp.2248-2254, April 2015.

[16] F. Seco, J. M. Martin, and A. R. Jimenez, "Improving the accuracy of magnetostrictive linear position sensors," IEEE Trans. Inst. \& Meas., vol. 58, no. 3, pp. 722-729, March 2009.

[17] H. Sumali, E. P. Bystrom, and G. W. Krutz, "A displacement sensor for nonmetallic hydraulic cylinders," IEEE Sens. J., vol. 3, no. 6, pp. 818826, Dec. 2003.

[18] E. G. Bakhoum, and M. H. M. Cheng, "High-sensitivity inductive pressure sensor," IEEE Trans. Inst. \& Meas., vol. 60, no. 8, pp. 29602966, Aug. 2011.

[19] S.-H. Yang, K. Hirata, T. Ota and Y. Kawase, "Impedance linearity of contactless magnetic-type position sensor", IEEE Trans. Magn., vol. 53, no. 6, 8001204, Jun. 2017.

[20] K. R. Sandra, B. George, and V. Jagadeesh Kumar, "A nonintrusive magnetically coupled sensor for measuring liquid level," IEEE Trans. Ins. \& Meas., vol. 69, no. 10, pp. 7716-7724, Oct. 2020.

[21] A. Grima, M. Di Castro, A. Masi, and N. Sammut, "Design enhancements of an ironless inductive position sensor," IEEE Trans. Ins. \& Meas., vol. 69, no. 4, pp. 1362-1369, Apr. 2020.

[22] B. A. Reinholz, and R. J. Seethaler, "Design and validation of a variable reluctance differential solenoid transducer," IEEE Sens. J., vol. 19, no. 23, pp. 11063-11071, Dec. 2019.

[23] L. Sun, J. Taylor, X. Guo, M. Cheng, and A. Emadi, “A linear position measurement scheme for long-distance and high-speed applications," IEEE Trans. Ind. Elect., vol. 68, no. 5, pp. 4435-4447, My 2021.

[24] M. Mirzaei, P. Ripka, and V. Grim, "A novel position sensor with a conical iron core," IEEE Trans. Inst. \& Meas., vol. 69, no. 11, pp. 9178 9189, Nov. 2020.

[25] https://www.ansys.com/products/electronics/ansys-maxwell, Accessed on 06.04.2021

[26] E. Both, "The permeability of silicon-iron at very low flux densities," Trans. American Inst. Elec. Eng., P. I: Comm. \& Elect., vol. 72, no. 5, pp. 656 - 664, Nov. 1953

[27] Z. Liu, A. R. Eastham, and G. E. Dawson, "Further studies on an improved finite element method for moving conductor eddy current problems," IEEE Trans. Mag., vol. 30, no. 5, pp. 2984-2987, Sep. 1994

[28] N. Allen, D. Rodger, P. C. Coles, S. Street, and P. J. Leonard, “Towards increased speed computations in 3D moving eddy current finite element modelling," IEEE Trans. Mag., vol. 31, no. 6, pp. 3524-3526, Nov. 1995

[29] M. Mirzaei, P. Ripka, A. Chirtsov, and J. Vyhnanek, "Eddy current linear speed sensor," IEEE Trans. Mag., vol. 55, no. 1, 4000304, Jan. 2019

[30] D. Rodger, "Modelling movement in electrical machines," IEEE Trans. Mag., 2021 (Early access).

[31] M. Lu, Y. Xie, W. Zhu, A. Peyton, and W. Yin, "Determination of the magnetic permeability, electrical conductivity, and thickness of Ferrite metallic plates using a multifrequency electromagnetic sensing system," IEEE Trans. Ind. Inf., vol. 15, no. 7, pp. 4111-4119, July 2019.

[32] M. Lu, R. Huang, W. Yin, Q. Zhao, and A. Peyton, "Measurement of permeability for ferrous metallic plates using a novel lift-off compensation technique on phase signature," IEEE Sens. J., vol. 19, no 17, pp. 7440-7446, Sept. 2019. 


\section{PREPRINT}

Final paper:

IEEE Sensors Journal21 (2021), 22899 - 22907, 10.1109/JSEN.2021.3105879

[33] P. Veeraian, U. Gandhi, and U. Mangalanathan, "Fractional order linear variable differential transformer: design and analysis," Int. J. Electron. \& Commun. $(A E \ddot{U})$, vol. 79, pp. 141-150, 2017 